\title{
Pedigree analysis of Santa Inês sheep and inbreeding effects on performance traits
}

\author{
Ana Carla Borges Barbosa ${ }^{\text {a }}$ \\ Gabrieli de Souza Romano ${ }^{\text {a }}$ \\ Jonatan Mikhail Del Solar Velarde ${ }^{\text {a }}$ \\ José Bento Sterman Ferraz ${ }^{b}$ \\ Víctor Breno Pedrosa ${ }^{\mathrm{c}}$ \\ Luís Fernando Batista Pinto ${ }^{a^{*}}$
}

${ }^{a}$ Universidade Federal da Bahia, Escola de Medicina Veterinária e Zootecnia, Av. Adhemar de Barros, 500, Ondina, Salvador - BA, 40170-110 . Brazil.

${ }^{\mathrm{b}}$ Universidade de São Paulo. Faculdade de Zootecnia e Engenharia de Alimentos. Brazil.

${ }^{\mathrm{c}}$ Universidade Estadual de Ponta Grossa. Departamento de Zootecnia. Av. Brazil.

*Corresponding author: luisfbp@gmail.com

\begin{abstract}
:
Population parameters such as effective population size and coefficients of inbreeding are important information of a population but have rarely been studied in Santa Inês sheep. Therefore, this study aimed to estimate population parameters in a Santa Inês sheep flock and the inbreeding effect on performance traits. A dataset with 11,564 animals, born from 2003 to 2011, was recorded for weights at birth (BW1), 60 (BW60), 180 (BW180) and 270 (BW270) days of age, daily weight gain from birth to $60 \mathrm{~d}$ (DWG1), 60 to $180 \mathrm{~d}$ (DWG2), and 60 to $270 \mathrm{~d}$ (DWG3). Percentages of animals with known pedigrees decreased over generations, from $70 \%$ in the first generation to less than $5 \%$ in the third. The effective population size decreased from 665 in 2004 to 45 in 2010. The effective number founders and ancestors were 285 and 273, respectively. Furthermore, the average relatedness coefficient was $0.47 \%$. The highest frequency of inbred animals was concentrated between 0 and $10 \%$ of the inbreeding coefficient and only 263 animals
\end{abstract}


showed F>10 \%. The inbreeding coefficient had its lowest value in $2004(0.19 \%)$ and a highest value in $2008(2.86 \%)$. Significant inbreeding effect was found for BW1 (0.0054 $\pm 0.0015)$, DWG2 (-0.9837 \pm 0.3025$)$, and DWG3 (-0.5628 \pm 0.2377$)$, while the analysis of breeding values indicated significant inbreeding depression for all traits, except DWG1. Results suggested that inbreeding had a negative effect on growth traits. To avoid losses in these traits it is necessary to mate non-related sires and dams.

Key words: Ancestors, Effective population size, Relatedness, Variability.

Received: 16/05/2018

Accepted: 23/03/2019

Every breeding program depends on the genetic variability in the population, but it is often neglected. One of the methods used to evaluate the impact of selection on the genetic variability is studying the population genetic structure, which can be done through pedigree analysis ${ }^{(1)}$. The effective population size $(\mathrm{Ne})$ is a parameter widely used to indicate risk of inbreeding depression or even extinction risk. In the last $50 \mathrm{yr}$, the effective population size of several sheep breeds has drastically decreased, leading in some cases to inbreeding depression ${ }^{(2,3,4)}$. Moreover, several sheep breeds were extinct in the 20th century due to reduction of $N e$. Of the 1,495 sheep breeds recorded up to december 1999, only 656 were not at risk of extinction until that time ${ }^{(5)}$.

Another important genetic population parameter is the number of ancestors explaining the genetic variability of a breed, because many commercial breeds usually have a reduced number of sires in mating. There are previous studies reporting large differences between the total number of ancestors and the number of ancestors that explain $50 \%$ of the genetic variability in different sheep breeds ${ }^{(6-9)}$. Additionally, the ratio between the effective number of founders $(f e)$ and the effective number of ancestors $(f a)$ indicates whether a population is under bottleneck effect. Examples of strong bottleneck effect have been observed in some sheep breeds ${ }^{(1,9)}$.

The coefficient of inbreeding expresses the probability that two alleles at one locus will be identical by descent ${ }^{(10)}$. Inbreeding causes a reduction in individual genetic merit for some productive traits, possibly due to the increase in homozygous genotypes for deleterious recessive alleles or a reduction of heterozygous genotypes ${ }^{(10)}$. However, the depressive effect is relatively minor at low levels of inbreeding. Therefore, monitoring of inbreeding is indicated for maintenance or reduction of inbreeding level of a population $^{(11)}$. An increase in the average inbreeding coefficient along generations has been observed in some sheep breeds ${ }^{(6,8)}$, and the most efficient way to control long-term 
inbreeding is to use breeding flocks with low average relatedness (AR). Thus, AR is another important parameter in population genetics.

Estimates of population parameters have been rarely reported for Santa Inês sheep ${ }^{(12,13)}$ and the only one study reported estimates of inbreeding effect on phenotypic traits ${ }^{(12)}$. These authors estimated inbreeding effects only for body weight traits, but did not estimated such effects on breeding values. Thus, the inbreeding effect on many traits and their breeding values remains unknown for Santa Inês sheep. The present study aimed to evaluate the genetic population structure of Santa Inês flocks, through pedigree information, and to estimate the effect of inbreeding on growth traits as well as for estimates of breeding values.

\section{Dataset}

An initial dataset was preliminary edited based on a file containing 11,781 animals with productive information and 12,322 animals in the pedigree, belonging to 16 different flocks. After consistency analysis, animals with missing productive information or without genetic connection between at least two different flocks were discarded. Records with errors or incomplete information or contemporary groups (CGs) with fewer than five animals with valid measurements were eliminated. As well as CGs in which the animals were the offspring of only one sire and the information was outside the acceptable range, i.e., 3 standard deviation above or below the mean of the trait, were also removed. Additionally, records were checked to ensure that: there were no duplicate records; no progeny was born before neither of their two parents; progeny only appeared as progeny, but not as sire and/or dam in the same record; sires only appeared as sires, but not as dams; dams only appeared as dams, but not as sires.

The final dataset included 11,564 animals in the pedigree, born from 2003 to 2011, which is maintained by the Sergipe State Association of Goat and Sheep Breeders (Associação Sergipana de Criadores de Caprinos e Ovinos - ASCCO). Traits recorded were weights at birth (BW1), 60 (BW60), 180 (BW180), and 270 (BW270) days of age. Daily weight gains were calculated from birth to 60 (DWG1), 60 to 180 (DWG2), and 60 to 270 (DWG3) days of age.

\section{Population parameters}

The software ENDOG ${ }^{(14)}$ was used to estimate inbreeding coefficient $(\mathrm{F})^{(15)}$, effective population size $(\mathrm{Ne})^{(14)}$ and average relatedness coefficient (AR). POPREP ${ }^{(16)}$ was used to estimate effective number of founders (fe), ancestors $(f a)$, effective number of founders genomes (fge) and number of generations traced (g). Additionally, it was estimated the genetic diversity loss average due to bottlenecks and genetic drift. A complete description of these parameters can be found in Gutiérrez and Goyache ${ }^{(14)}$. 


\section{Breeding value prediction and Inbreeding effect analysis}

All traits were tested for data normality applying Shapiro-Wilk test, at 5\% significance level, using Statistical Analysis System ${ }^{(17)}$, before estimating genetic parameters. Estimates of variance components and breeding values were obtained by restricted maximum likelihood (REML), with a multitrait animal model, using the software VCE6 $^{(18)}$ (for variance components) and PEST ${ }^{(19)}$ (for breeding values). In this analysis, the matrix model can be described as follows:

$y=\mathbf{X} b+\mathrm{Z} a+\mathrm{M} m+e$

where:

$\boldsymbol{y}$ is the vector of phenotypic values;

$\boldsymbol{b}$ is the vector of fixed effects of contemporary group, and the covariates dam's age and animal's age; $\mathbf{X}$ is the incidence matrix that relates the observations in $\boldsymbol{y}$ to fixed effects in $\boldsymbol{b}$;

$\boldsymbol{a}$ is the vector of direct additive random effect; $\mathbf{Z}$ is the incidence matrix that relates the observations in $\boldsymbol{y}$ to direct additive random effects in $\boldsymbol{a}$;

$\boldsymbol{m}$ is the vector of maternal additive random effect;

$\mathbf{M}$ is the matrix that relates the observations in $\boldsymbol{y}$ to maternal additive effect in $\boldsymbol{m}$;

$\boldsymbol{e}$ is the vector of random residual term.

The maternal component Mm was adjusted only for the traits BW1, BW60 and DWG1. The dataset used in this study had a low number of calves per ewe. Thus, the permanent maternal effect and the litter environmental effect were tested but presented problems such as non-convergence or inconsistent estimates of parameters. Therefore, it was chose not to include those effects in the final model. In addition, the dataset showed a low number of inbred Dams and, therefore, it was not include this effect in the model.

The assumptions of the models for analyzes could be simply represented as follows:

$$
E\left[\begin{array}{c}
y \\
a \\
m \\
e
\end{array}\right]=\left[\begin{array}{c}
X b \\
0 \\
0 \\
0
\end{array}\right] ; \text { e } V\left[\begin{array}{c}
a \\
m \\
e
\end{array}\right]=\left[\begin{array}{ccc}
G & G x M & 0 \\
G x M & M & 0 \\
0 & 0 & R
\end{array}\right]
$$

The (co)variance matrix for additive genetic effects is $G=G \otimes A$, where $A$ is the relationship matrix and $\mathrm{G}$ is the additive genetic (co)variance matrix. The (co)variance matrix for maternal genetic effects is $M=M \otimes A$, where $M$ is the genetic maternal (co)variance matrix. $\mathrm{R}=\mathrm{I} \otimes \mathrm{R}_{0}$ is the residual (co)variance matrix between the seven traits. GxM is the covariance between genetic additive and maternal effects. 
The contemporary group (CG) consisted of animals from the same farm (45 levels), sex (male or female), birth type (single or twins), year (2003 to 2011), and season of birth (dry or rainy). Contemporary groups with less than three animals were removed from the analysis. Table 1 shows the number of CG per trait and descriptive statistics for all traits.

Table 1: Sample size (N), number of contemporary groups (CG), mean and standard deviation (SD) of the traits

\begin{tabular}{|c|c|c|c|c|}
\hline Traits $^{1}$ & $\mathbf{N}$ & CG & Mean & SD \\
\hline Birth weight & 10232 & 291 & 3.63 & 0.80 \\
\hline Weight at $60 \mathrm{~d}$ (weaning) & 6277 & 319 & 15.94 & 5.77 \\
\hline Weight at $180 \mathrm{~d}$ & 4541 & 403 & 31.9 & 11.16 \\
\hline Weight at $270 \mathrm{~d}$ & 3328 & 374 & 39.7 & 14.5 \\
\hline Daily weight gain from birth to $60 \mathrm{~d}$ & 5786 & 319 & 171.73 & 64.87 \\
\hline Daily weight gain from 60 to $180 \mathrm{~d}$ & 3229 & 403 & 149.43 & 67.84 \\
\hline Daily weight gain from 60 to $270 \mathrm{~d}$ & 1863 & 374 & 69.17 & 26.83 \\
\hline Dam & 4742 & ---- & ---- & ---- \\
\hline Sire & 391 & ---- & ---- & ---- \\
\hline
\end{tabular}

${ }^{1}$ Weight and weight gain were measured in kilograms.

For testing inbreeding effect on the phenotypic values it was used the mixed model:

$$
y_{i j}=\mu+C G_{i}+\alpha_{i j}(I)+\beta_{i j}(D)+\delta_{i j}(A)+\gamma_{i j}(G)+e_{i j}
$$

where:

$y_{i j}$ is the phenotypic value of trait; $\mu$ is the global mean; $C G_{i}$ is the fixed effect of contemporary group;

$\boldsymbol{\alpha}_{\boldsymbol{i} j}(\boldsymbol{I})$ is the fixed effect of covariate inbreeding coefficient level;

$\boldsymbol{\beta}_{\boldsymbol{i j}}(\boldsymbol{D})$ is the fixed effect of covariate dam's age;

$\boldsymbol{\delta}_{i j}(\boldsymbol{A})$ is the fixed effect of covariate animal's age;

$\gamma_{i j}(G)$ is the random effect of covariate breeding value;

$\boldsymbol{e}_{\boldsymbol{i} \boldsymbol{j}}$ is the residual random term. For DWG2 and DWG3 both initial and final animal's age were included in the model as fixed effect.

In addition, inbreeding effect on breeding values were also tested and the model was as follows: $y_{i j}=\mu+\alpha_{i j}(I)+e_{i j}$ where: $y_{i j}$ is the breeding value of trait; $\mu$ is the global mean; $\alpha_{i j}(I)$ is the fixed effect of covariate inbreeding coefficient level; and $e_{i j}$ is the residual term. The mixed procedure of SAS software ${ }^{(17)}$ was used to estimate inbreeding regression coefficients for all traits. Significance level to declare inbreeding effect was $5 \%$. 


\section{Pedigree completeness}

Percentages of animals with known pedigrees decreased with the passing of the generations, from over 70\% in the first generation to less than 5\% in the third (Figure 1). This result may be a consequence of ASCCO had been started the phenotypic and pedigree records recently (about 3-4 generations), which may explain the little-known ancestry of the animals studied here. Loss of information from one generation to another in the present study was higher than those reported in previous studies with Santa Inês flocks $^{(12,13)}$. Pedrosa et ${ }^{(12)}$ found known ancestry from parents to great-grandparents of $77,59.5$, and $38.75 \%$, while Teixeira Neto et $a l^{(13)}$ found $80.84,73.78$, and $67.75 \%$. Previous studies about other sheep breeds reported varied levels of pedigree completeness. High levels were reported for Bharat Merino sheep, with values of 91.01, $82.63,74.91,67.10$, and $57.78 \%$ for the first, second, third, fourth, and fifth generation, respectively ${ }^{(8)}$. However, for other sheep breeds were reported pedigree completeness less than those observed in the present study, especially in the first generation back $(11.88 \%$ for sire and $69.38 \%$ for dam) in Guilan sheep ${ }^{(20)}$, and (57\% for sire and $15 \%$ for dam) in Mehraban sheep ${ }^{(21)}$.

Figure 1: Pedigree and level of identification of the ancestors up to the third generation

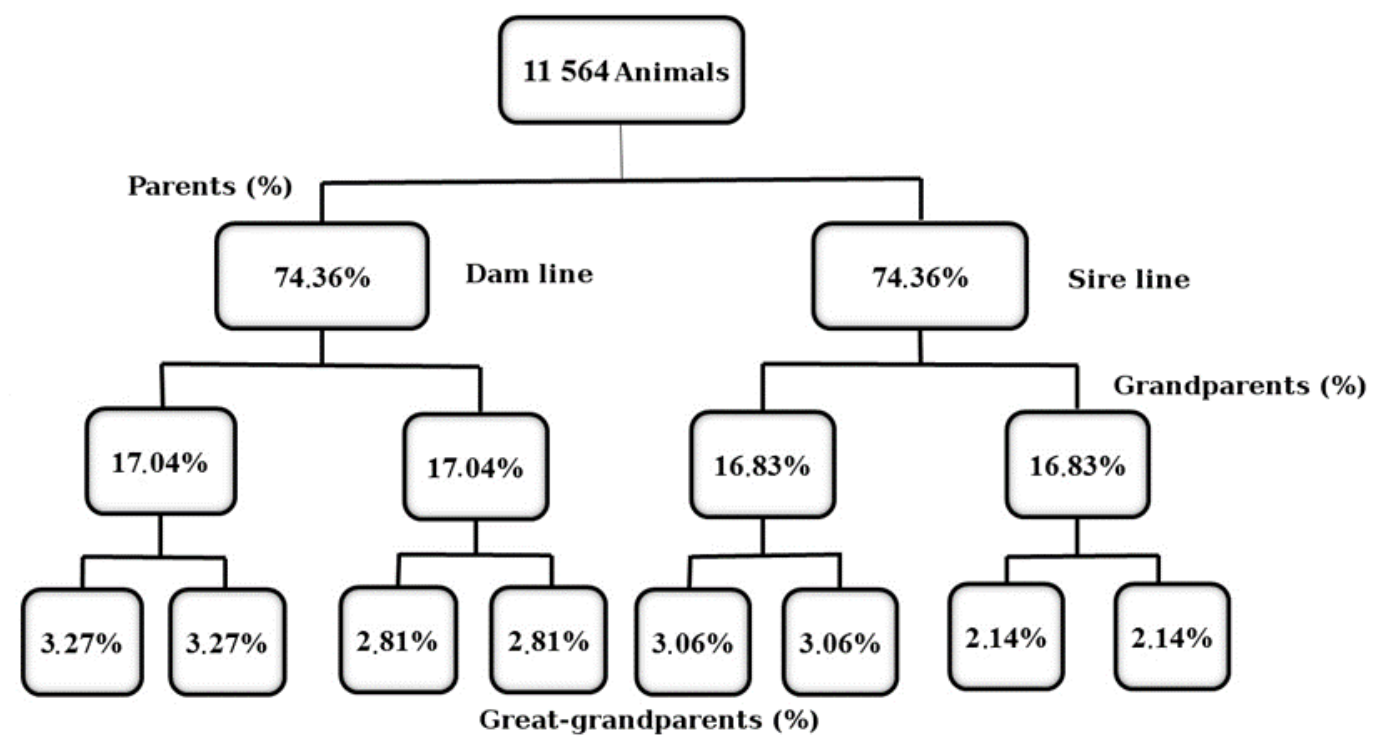

The number of equivalent generations is the parameter that best describes the quality of a pedigree and higher value for this parameter indicates a more completeness pedigree. In the present study, this value was low (Table 2) indicating that, even with a reasonable amount of information (11,564 individuals), the average relatedness was less in this Santa Inês dataset. In previous studies with Santa Inês, higher values were found, $2.26^{(12)}$ and $4.67^{(13)}$, due to higher pedigree completeness. A low number of equivalent generations is common in sheep breeds with early conservation and breeding programs ${ }^{(6)}$, resulting in pedigrees with a low degree of depth and incomplete information. For this reason, a 
reduced number of equivalent generations was also reported in several sheep breeds $^{(2,6,9,21)}$.

Table 2: Genetic parameters of the gene origin for Santa Inês Flocks in Northeast of Brazil

\begin{tabular}{lc}
\hline Genetic parameters & Value \\
\hline Reference population & 11,564 \\
Number of ancestors & 3,984 \\
Effective number of founders $\left(f_{e}\right)$ & 285 \\
Number of founding animals & 486.84 \\
Effective number of ancestors $\left(f_{a}\right)$ & 273 \\
Number of ancestors explaining 50\% & 146 \\
Effective number of founders genomes $\left(f_{g e}\right)$ & 35.71 \\
Average of genetic diversity loss & 0.0094 \\
Inbreeding (F) & $1.40 \%$ \\
Average relatedness coefficient (AR) & $0.47 \%$ \\
Average number of equivalent generations & 0.94 \\
Average number of complete generations & 0.83 \\
Average number of maximum generations & 1.09 \\
Inbreeding increment $(\Delta \mathrm{F})$ in equivalent generations & 0.95 \\
Inbreeding increment $(\Delta \mathrm{F})$ in complete generations & 0.97 \\
Inbreeding increment $(\Delta \mathrm{F})$ in maximum generations & 0.73 \\
Effective population size $($ Ne) in equivalent generations & 52.62 \\
Effective population size $($ Ne) in complete generations & 51.28 \\
Effective population size $($ Ne) in maximum generations & 68.83 \\
Generation Interval Father-Son & 3.46 \\
Generation Interval Father-Daughter & 3.33 \\
Generation Interval Mother-Son & 3.40 \\
Generation Interval Mother-Daughter & 3.28 \\
\hline
\end{tabular}

\section{Structure and genetic diversity}

The effective population size ( $\mathrm{Ne}$ ) changed with time (Figure 2), being highest in 2004 (665) and lowest in 2010 (45). The largest effective size was observed for the maximum generation (Table 2). The variation in effective population size $(\mathrm{Ne})$ over time has also been observed in other sheep breeds. Values of $N e$ ranging from 41.8 to 31.3 in Morada Nova sheep ${ }^{(22)}$, while values of $N e$ from 280.2 to 12.4 for Segureña sheep has been reported ${ }^{(6)}$. Therefore, the average effective population size $\left(\bar{N}_{e}\right)$ is a better reference and it was close to 50 when calculated for complete and equivalent generations in the present study (Table 2) and higher than 60 for the maximum generations. According to $\mathrm{FAO}^{(23)}$, the desired effective population size is about 50 animals per generation, to restrict a rate 
of inbreeding of $1 \%$ per generation. Thus, the $N e$ values by year observed for the Santa Inês flocks in the present study (Figure 2), as well as $\bar{N}_{e}$ (Table 2) indicate a risk situation, but inbreeding increases were less than $1 \%$ for complete, equivalent and maximum generations (Table 2), which is in line with FAO recommendations to avoid the risk of extinction. The $\mathrm{Ne}$ decrease and simultaneous increase of F (Figure 2) may be due to the registration of animals without pedigree information or the intense use of some sires in the ASCCO farms, since the average breeding values for DWG3 tended to increase as Ne decreases and F increases (note similar line curves of DWG3 and F in the Figure 2).

Figure 2: Average inbreeding $(\mathrm{F})$, effective population size $(\mathrm{Ne})$ and average breeding values for DWG3 per year of birth

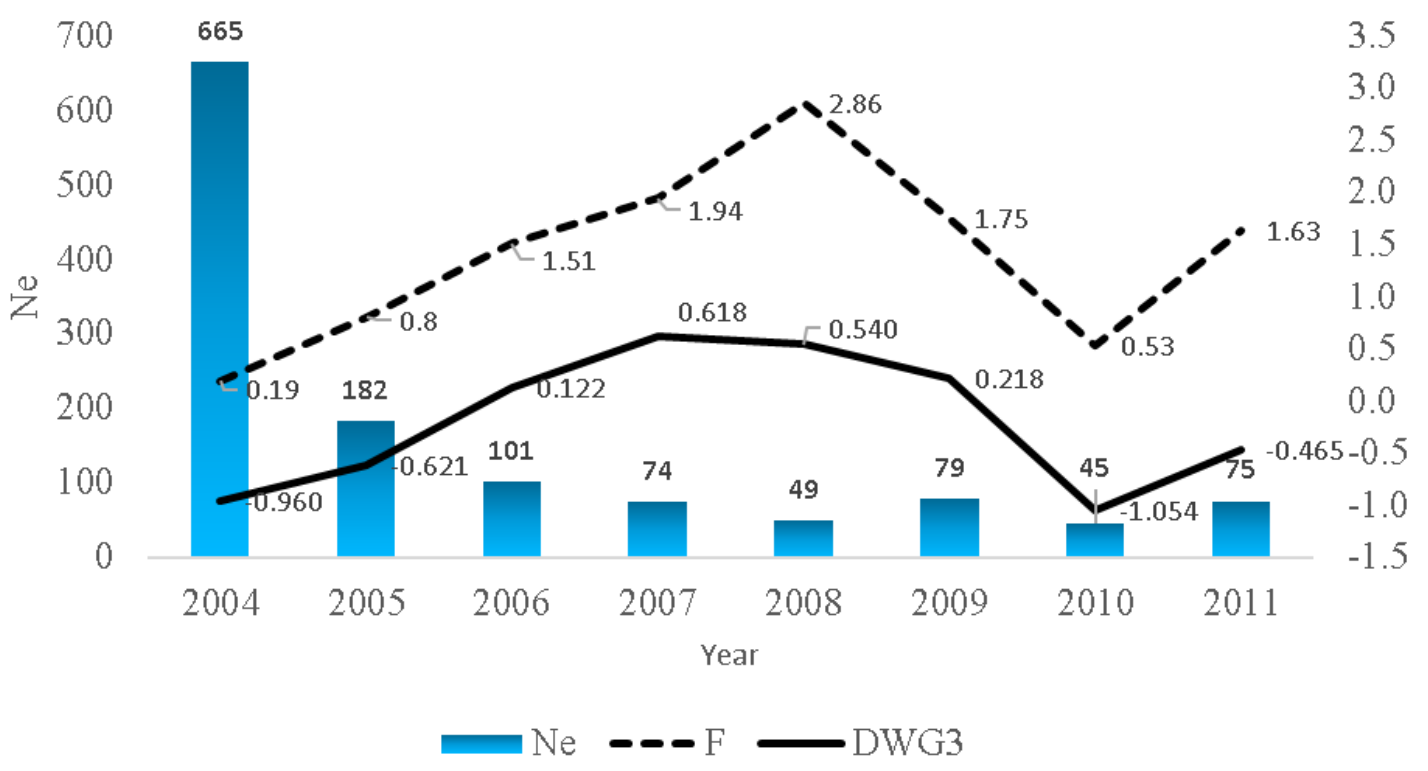

A reference population of 11,564 Santa Inês sheep was evaluated, with 3,984 ancestors. In this population, the effective number of founders $(f \mathrm{e})$ was 285 , while the number of founding animals was 486.84 . The number of ancestors explaining $50 \%$ of the genetic variation was 146 and the effective number of ancestors was 273 . The effective number of founders genomes $\left(f_{g e}\right)$ was 35.71. Therefore, some Santa Inês sires were used more intensely, in detriment to others, which may have contributed to the loss of genetic variability. All ancestors would contribute in the same way throughout the generations, but for many sheep breeds the total number of ancestral is much larger that number of ancestral explaining $50 \%$ of genetic variability ${ }^{(8,9,22)}$.

Largest inbreeding increment was observed in equivalent generation (Table 2). The highest number of inbred animals was concentrated between 0 and $10 \%$ of the inbreeding coefficient and just 263 animals showed F>10\%. Generation interval for each of the four parent-offspring pathways demonstrated an average of 3.37 (Table 2). Estimates of average inbreeding coefficient ranged from zero to $6.25 \%$ along the generation (Table 3 ) 
and average inbreeding was $1.40 \%$ when only inbred animals were considered. The estimates of average relatedness coefficient ranged from 0.22 to $0.52 \%$ along the generation (Table 3) and general average relatedness coefficient was $0.47 \%$. The inbreeding coefficient had its lowest value in $2004(0.19 \%)$ and a higher value in 2008 $(2.86 \%)$ (Figure 2).

Table 3: Number of animals $(\mathrm{N})$ per generation with their respective average inbreeding coefficient (F) and average relationship coefficient (AR)

\begin{tabular}{|c|c|c|c|}
\hline Generations & $\mathbf{N}$ & F $(\%)$ & $\operatorname{AR}(\%)$ \\
\hline 1 & 7,562 & 0.00 & 0.22 \\
\hline 2 & 2,901 & 0.88 & 0.45 \\
\hline 3 & 844 & 2.42 & 0.51 \\
\hline 4 & 210 & 3.81 & 0.51 \\
\hline 5 & 57 & 3.82 & 0.52 \\
\hline 6 & 1 & 6.25 & 0.43 \\
\hline
\end{tabular}

Ideally, $f_{e}$ equals $f_{a}$, or the difference is always as low as possible. Ratios much higher than 1.0 indicate a strong bottleneck effect, which may be due to small number of sires used in mating. This ratio in the present study $(1.04 \%)$ suggests that the majority of ancestors were founders and an insignificant genetic bottleneck. Despite the good felfa ratio in the present study, $f_{e}$ and $f_{a}$ had values much lower than the reference population and ancestors (Table 2), indicating that the animals evaluated here have a narrow genetic origin. Another study with Santa Inês reported a higher (1.35) $\mathrm{fe} / \mathrm{fa} \mathrm{ratio}^{(12)}$, demonstrating genetic variability reduction caused by the imbalance between ancestral and founders and the higher bottleneck effect. For other sheep breeds, a $f e / f a$ close to one was also reported, such as 1.0 in Morada Nova sheep ${ }^{(22)}$, and 1.18 in Iran-black sheep ${ }^{(7)}$, and 1.12 in Segureña sheep ${ }^{(6)}$. However, large values were also reported in Xalda sheep $(2.02)^{(1)}$ and in Kermani sheep (2.07) ${ }^{(9)}$. Finally, an average of genetic diversity loss of 0.0094 was detected over the studied period, demonstrating that genetic drift was significant to result in loss of genetic diversity in this population.

Inbreeding values above $10 \%$ are associated with decreased performance in sheep ${ }^{(24)}$. It was observed few animals $(2.27 \%$ ) with consanguinity higher than $10 \%$, and a maximum F value of $37.5 \%$, while several animals $(97.73 \%)$ were not inbreed or showed an inbreeding coefficient less than $10 \%$. These values are similar to those reported for other sheep breeds ${ }^{(8,25)}$. In a study with Bharat Merino sheep, $97.62 \%$ of animals were noninbreed or showed $\mathrm{F}<10 \%$, and the highest individual inbreeding was $32.81 \%{ }^{(8)}$. In Iranian Shal sheep, $93.72 \%$ of animals to be non-inbred or $\mathrm{F}<10 \%$, with a maximum individual inbreeding of $31.25 \%{ }^{(25)}$. It is noteworthy that low pedigree completeness may 
have underestimated individual inbreeding coefficients in the present study. Previous studies about Santa Inês sheep, with better pedigree completeness, found maximum inbreeding of $41.02 \%^{(12)}$ and $54.83 \%^{(13)}$, respectively; both studies have shown that the number of inbred animals increases significantly after the first years of pedigree control. The average inbreeding coefficient of the population (inbred and non-inbred animals) was $0.36 \%$, but average inbreeding coefficient for inbred animals was $1.41 \%$. Higher values of population average inbreeding $2.33 \%^{(12)}$ and $6.92 \%^{(13)}$ were reported for Santa Inês sheep. In these studies, average inbreeding coefficients were $10.74 \%^{(12)}$ and $12.57 \%{ }^{(13)}$ when only inbred animals were used. The lowest value found in the present study may be due to low pedigree completeness, especially in the first years, which makes computing inbreeding coefficient difficult. Small average inbreeding coefficients were reported in other sheep breeds with low pedigree completeness. Previous studies reported average inbreeding coefficients of $0.15,1.6$ and $0.60 \%$ for whole analyzed pedigree of the Guilan $^{(20)}$, Baluchi ${ }^{(2)}$, and Segureña ${ }^{(6)}$ sheep breeds, respectively.

The increase in inbreeding throughout the generations (Table 3) may be reflecting a better flock pedigree control and consequently higher database quality, because the inbreeding coefficient depends on the number of known generations. The inbreeding increment $(\Delta F)$ in the present study was low for all of the generations traced (Table 2), suggesting that the Santa Inês flocks under investigation were in good condition. An increase in the average inbreeding coefficient along generations was also observed in other sheep breeds ${ }^{(6,8)}$. An increase from zero to 7.09 (from the initial to the fourth generation) in Segureña sheep was reported ${ }^{(6)}$, while an increase from zero to 1.54 (from the initial to the sixth generation) was reported to Bharat Merino sheep ${ }^{(8)}$. The low AR values obtained in the present study (Table 3), show that the flocks are in a good situation, increasing the probability of mating among unrelated individuals. Another Santa Inês dataset ${ }^{(12)}$ also showed a low estimate for AR $(0.73 \%)$, evidencing the great variability of this breed.

\section{Inbreeding effect on phenotype and breeding values}

For phenotypic values, the individual inbreeding had no effect $(P>0.05)$ on BW60, BW180, BW270, and DWG1 (Table 4), but significant effects $(P<0.05)$ were observed for BW1 (0.0054 \pm 0.0015$)$, DWG2 (-0.9837 \pm 0.3025$)$, and DWG3 $(-0.5628 \pm 0.2377)$. For breeding values, depression inbreeding effect were significant $(P<0.05)$ for all traits, except DWG1. For the Santa Inês sheep, only one previous study ${ }^{(12)}$ tested inbreeding effect on phenotypic traits, but they evaluated only BW1, BW60 and BW180. They observed a reduction of 34,52 , and 204 grams per $\% \Delta \mathrm{F}$ (equivalent to a traditional inbreeding coefficient of $2.2 \%$ when 2.26 generations in the pedigree are known) in the weight of Santa Inês for BW1, BW60, and BW180, respectively. The present analysis for record traits did not confirm these findings, because it was found a positive inbreeding effect on BW1, where each $1 \%$ of inbreeding increased $5.4 \mathrm{~g}$ in this weight, and no significant effects were observed for BW60, BW180 and BW270 (Table 4). Several previous studies with other sheep breeds reported depressive inbreeding effect on birth 
weight $^{(21,26,27)}$ where each $1 \%$ of inbreeding resulted in decreases ranging from $-0.7 \mathrm{~g}$ per $1 \% \mathrm{~F}$ in Polish Olkuska sheep ${ }^{(26)}$ to $-51 \mathrm{~g}$ per $1 \% \mathrm{~F}$ in Thalli sheep ${ }^{(27)}$. For other pre and post-weaning body weights, there are many results indicating depressive effects in different sheep breeds as well. Depression-inbreeding effect for BW60, with values range from -33 to $-48 \mathrm{~g}$ per $1 \% \mathrm{~F}$ were reported ${ }^{(27,28)}$. However, studies with Iranian Shal sheep $^{(25)}$ and Segureña sheep ${ }^{(6)}$ did not any significant inbreeding effect on body weight.

Table 4: Regression coefficients of the effects of inbreeding on the performance traits

\begin{tabular}{lllllll}
\hline & \multicolumn{3}{c}{ Phenotype value } & \multicolumn{4}{c}{ Breeding value } \\
\hline Trait & Estimate & $\begin{array}{l}\text { Standard } \\
\text { Error }\end{array}$ & $P$-value & Estimate & $\begin{array}{l}\text { Standard } \\
\text { Error }\end{array}$ & $\boldsymbol{P}$-value \\
\hline BW at birth & 0.0054 & 0.0015 & 0.0004 & -0.0049 & 0.0006 & $<0.0001$ \\
BW at 60 d & 0.0252 & 0.0132 & 0.0555 & -0.0162 & 0.0030 & $<0.0001$ \\
BW at 180 d & -0.0568 & 0.0299 & 0.0575 & -0.0347 & 0.0104 & 0.0009 \\
BW at 270 d & -0.0623 & 0.0430 & 0.1469 & -0.0448 & 0.0131 & 0.0006 \\
DWG from birth to 60 d & -0.2318 & 0.2200 & 0.2921 & -0.0461 & 0.0573 & 0.4213 \\
DWG from 60 to 180 d & -0.9837 & 0.3025 & 0.0012 & -0.2846 & 0.0868 & 0.0011 \\
DWG from 60 to 270 d & -0.5628 & 0.2377 & 0.0180 & -0.0524 & 0.0212 & 0.0137 \\
\hline
\end{tabular}

In some previous studies, no-significant effects are many times attributed to the low level of inbreeding of the animals as consequence of low pedigree completeness. In the present study, the dataset had also low pedigree completeness (Figure 1); consequently, large number of animals $(7,562)$ showed F close to zero. Another hypothesis for no-significant effect is the reduced number of animals showed both $\mathrm{F}>0$ and phenotypic record. To avoid this second problem, we decided to evaluate the effect of inbreeding on the breeding values. The results (Table 4) indicated a significant inbreeding effect on breeding values of all body weights (BW1, BW60, BW180 and BW270). In addition, the regression coefficients were negative, which is more consistent with previous studies reported in sheep ${ }^{(26,27,28)}$.

Regression coefficients for DWG2 and DWG3 were higher than those $(-0.263 \pm 0.116)$ reported for daily weight gain from 90 to 365 in Sandyno sheep ${ }^{(4)}$, and lower than those found for daily weight gain from 90 to $180(-1.810 \pm 0.017)$ and from 90 to $365(-1.345$ \pm 0.083 ) in Baluchi sheep ${ }^{(2)}$. Finding effect for daily weight gain and no effect for body weight seems incoherent, but it is easy to explain. The number of animals with records for BW60, BW180 and BW270 was different from the number of animals with records for DWG2 and DWG3, because to calculate the daily weight gain we need the same animal to have four information (the initial and final BW, and the initial and final ages). 
It is not a reality for all animals in our dataset. When used breeding values this problem was resolved, because all animal has the estimates of breeding values for all traits. It is possible observed in Table 4 that this incoherence practically not existed when we estimated inbreeding effect on breeding values (Table 4), suggesting a more consistent result.

It could be observed that the evaluated population had a low pedigree completeness and small average inbreeding. This population presented a decrease in the effective population size over the generations and an increase of the endogamy, which can compromise its genetic variability. The inbreeding had significant effect on BW1, DWG2 and DWG3 when evaluated phenotypic records. When was evaluated breeding values, the inbreeding effect was significant for all traits, except for DWG1. Regression coefficients obtained for breeding values suggested a more consistent analysis, because they were negative and significant for both BW (all ages) and post-weaning DWG. On the other hand, positive and significant regression inbreeding coefficients was found only for BW1 (in phenotypic analysis), but it was not found similar results for this trait in breeding value analysis. In both analysis, the inbreeding effect on growth traits were mainly negative, which implies the need to avoid related mating on the studied flocks of Santa Inês sheep.

\section{Acknowledgments}

The authors thank to ASCCO for the dataset provided; to FAPESB for the scholarship of Ana Carla Borges Barbosa; and to CNPQ for the Productivity Scholarship for José Bento Sterman Ferraz, Victor Breno Pedrosa, and Luís Fernando Batista Pinto.

\section{Literature cited:}

1. Goyache F, Gutiérrez JP, Fernández I, Gomez E, Alvarez I, Díez J, Royo LJ. Using pedigree information to monitor genetic variability of endangered populations: the Xalda sheep breed of Asturias as an example. J Anim Breed Genet 2003;120:95103.

2. Gholizadeha M, Ghafouri-Kesbi F. Inbreeding depression in growth traits of Baluchi sheep. Small Ruminant Res 2016;144:184-190.

3. Yeganehpur Z, Roshanfekr H, Fayazi J, Beyranvand MH. Inbreeding depression on growth traits of Iranian Lori sheep. Rev Colomb Cienc Pec 2016;29:264-273. 
4. Venkataramanan R, Subramanian A, Sivaselvam SN, Sivakumar T, Sreekumar C, Iyue, M. Effect of inbreeding and individual increase in inbreeding on growth in Nilagiri and Sandyno breeds of sheep. Anim Genet Resour 2016;58:63-71.

5. Scherf BD. World watch list for domestic animal diversity. $3^{\text {rd }}$ ed., Italy, AO, 2000.

6. Barros EA, Brasil LHA, Tejero JP, Delgado-Bermejo JV, Ribeiro MN. Population structure and genetic variability of the Segureña sheep breed through pedigree analysis and inbreeding effects on growth traits. Small Ruminant Res 2017;149:128133.

7. Mokhtari MS, Shahrbabak MM, Esmailizadeh AK, Shahrbabak HM, Gutierrez JP. Pedigree analysis of Iran-Black sheep and inbreeding effects on growth and reproduction traits. Small Ruminant Res 2014;116:14- 20.

8. Gowane GR, Prakash V, Chopra A, Prince LLL. Population structure and effect of inbreeding on lamb growth in Bharat Merino sheep. Small Ruminant Res 2013;114:72-79.

9. Mokhtari MS, Shahrbabak MM, Esmailizadeh AK, Abdollahi-Arpanahi R, Gutierrez JP. Genetic diversity in Kermani sheep assessed from pedigree analysis. Small Ruminant Res 2013;114:202-205.

10. Lynch M, Walsh B. Genetics and analysis of quantitative traits. 1st Ed., USA, Sinauer Associates, 1998.

11. Breda FC, Euclides RF, Pereira CS, Torres RA, Carneiro PLS, Sarmento JLR, Torres Filho RA, Moita AKF. Endogamia e Limite de Seleção em Populações Selecionadas Obtidas por Simulação. Rev Bras Zootec 2004;33:2017-2025.

12. Pedrosa VB, Santana-Junior ML, Oliveira PS, Eler JP, Ferraz JBS. Population structure and inbreeding effects on growth traits of Santa Inês sheep in Brazil. Small Ruminant Res 2010;93:135-139.

13. Teixeira-Neto MRT, Cruz JF, Carneiro PLS, Malhado CHM, Faria HHN. Parâmetros populacionais da raça ovina Santa Inês no Brasil. Pesq Agropec Bras 2013;48:15891595.

14. Gutiérrez JP, Goyache F. A note on ENDOG: a computer program for analyzing pedigree information. J Anim Breed Genet 2005;122:172-176. 
15. Meuwissen TI, Luo Z. Computing inbreeding coefficients in large populations. Genet Sel Evol 1992;24:305-313.

16. Groeneveld E, Westhuizen BVD, Maiwashe A, Voordewind F, Ferraz JBS. POPREP: a generic report for population management. Genet Mol Res 2009;8(3):1158-1178.

17. SAS. SAS/STAT User's Guide (Release 13.1). Introduction to Mixed Modeling Procedures. USA, SAS institute Inc., 2013.

18. Groeneveld E, Kovač M, Mielenz N. VCE User's guide and reference manual (Release 6.0). Germany, 2010.

19. Groeneveld E, Kovac M, Mielenz N. PEST2 User`s guide and reference manual (Release 2.0). Germany, 2009.

20. Eteqadi B, Hossein-Zadeh NG, Shadparvar AA. Population structure and inbreeding effects on body weight traits of Guilan sheep in Iran. Small Ruminant Res 2014;119:45-51.

21. Yavarifard R, Hossein-Zadeh NG, Shadparvar AA. Population genetic structure analysis and effect of inbreeding on body weights at different ages in Iranian Mehraban sheep. J Anim Sci Tech 2014;56:34.

22. Rodrigues DS, Ribeiro MN, Oliveira SMP, Lima FAM, Villarroel ABS, Pacheco ACL, Santos LH. Estrutura populacional de um rebanho da Raça Morada nova como contribuição para a conservação. Cienc Rural 2009;19:103-110.

23. FAO. Secondary Guidelines for Development of National Farm Animal Genetic Resources Management Plans: Management of Small Populations at Risk. Italy, FAO, 1998.

24. Norberg E, Sorensen AC. Inbreeding trend and inbreeding depression in the Danish populations of Texel, Shropshire, and Oxford Down. J Anim Sci 2007;85:299-304.

25. Patiabadi Z, Varkoohi S, Savar-Sofla S. Inbreeding and inbreeding depression on body weight in iranian Shal sheep. Iran J Appl Anim Sci 2016;6:887-893.

26. Drobik W, Martyniuk E. Inbreeding and its impact on the prolific Polish Olkuska sheep population. Small Rumin Res 2016;137:28-33.

27. Hussain A, Akhtar P, Ali S, Younas M, Shafiq M. Effect of inbreeding on pre-weaning growth traits in Thalli sheep. Pak Vet J 2006;26:138-140. 
28. Analla M, Montilla JM, Serradilla JM. Study of the variability of the response to inbreeding for meat production in Merino sheep. J Anim Breed Genet 1999;116:481488. 